AGEING WITH A LEARNING DISABILITY:

A CRITICAL LITERATURE REVIEW

C. Victor ${ }^{1}$, V. Williams, $\mathrm{PhD}^{2}$, D. Kinnear, $\mathrm{PhD}^{3}, \mathrm{~S}$. Ryan ${ }^{4}$, 1. Brunel University London, Uxbridge, England, United

Kingdom, 2. University of Oxford, Oxford, UK, 3.

University of Glasgow, Glasgow, UK, 4. University of

Oxford, Oxford, UK

In the United Kingdom, there are an estimated 1.14 million people with a learning disability. Little is known about the experiences of this group of people as they age and how they conceptualise 'successful ageing'. We undertook a systematic literature review of the experience of ageing for adults with a learning disability and identified 65 papers published between 2001 and 2016 categorised into 6 domains health; activities of daily living and function; experiences of ageing; quality of life and well-being; autonomy and transitions. Most papers, 43, focused upon health/activities of daily living with 11 studies examining ideas about ageing, autonomy and transitions highlighted the lack of research looking at social inclusion and engagement social exclusion. We still lack a clear understanding as to what a good later life for older learning disabled people consists of and how, if at all, it differs from the rest of the population.

\section{ENGAGING SOCIAL SUPPORT IN FUTURE PLANNING FOR INDIVIDUALS WITH INTELLECTUAL DISABILITIES}

T.A. Nicoll ${ }^{1}$, S.H. Qualls, $\mathrm{PhD}^{2}, 1$. University of Colorado Colorado Springs, Colorado Springs, Colorado, United

States, 2. University of Colorado, Colorado Springs, CO, USA

Many adults with intellectual disabilities now outlive their parents due to their increased lifespan, yet parents report low rates of planning for the future. Although many barriers are known to impede planning, factors that facilitate planning are less known. The present study examines the effect of a social support intervention on future planning in a randomized control group design. Parents of adult children with intellectual disabilities were invited to a future planning workshop. Parents were randomly assigned to the control condition or the intervention condition. Several mixed analyses of covariance (ANCOVAs) were utilized to test the hypotheses. The workshop increased planning in both conditions, but no significant differences were found between conditions. Perceived social support increased in the intervention condition and decreased for controls. No effect of time or condition was found. Clinical and practical implications are discussed for improving rates of future planning for individuals with intellectual disabilities.

\section{THE EXPERIENCE OF PARENTING A CHILD WITH DISABILITY IN OLD AGE}

T. Band-Winterstein ${ }^{1}, \mathrm{H}$. Avieli, $\mathrm{PhD}^{2}, 1$. Department of Gerontology University of Haifa, Israel, Haifa, Hefa, Israel, 2. Ariel University, Israel

The current study aims to highlight the ways in which aging parents perceive their parental role to adult children with disabilities at this stage of their lives. An interpretive phenomenological analysis perspective was used. Data collection was performed through in-depth, semi structured interviews with 20 aging parents of children with developmental disabilities, followed by a content analysis. Four patterns of parental identity emerged: "Being happy is his responsibility; I did my part," embracing aging needs; "I can do part-time worrying," a gradual letting go of parental roles; "I'm worn out, but I keep going. What choice do I have?" bearing the brunt; "I'm an old woman changing diapers," full-time parents. The findings enable a deeper understanding of the various ways in which parents cope with aging alongside caring for an adult child with disability. Hence, this study can serve as a framework for developing differential intervention methods for these parents.

\section{SUPPORTING PIONEERS: BUILDING BETTER NETWORKS FOR ADULTS AGING WITH AUTISM}

D.A. Waldron ${ }^{1}$, C.E. Coyle, $\mathrm{PhD}^{2}$, J. Kramer, $\mathrm{PhD}^{3}$, D. Jeckel, MSW ${ }^{4}, 1$. Gerontology Department, University of Massachusetts Boston, Taunton, Massachusetts, United States, 2. Gerontology Department, University of Massachusetts Boston, Boston, MA, USA, 3. Institute for Community Inclusion, University of Massachusetts Boston, Boston, MA, USA, 4. The Asperger/Autism Network (AANE), Watertown, MA, USA

Although traditionally understood as a childhood condition, autism spectrum disorder (ASD) is a lifelong disorder present in both children and adults. However, many of the children with this disorder who were born during the last century and who are now reaching mid and later life did not receive formal diagnoses of ASD-leaving them facing the second half of life with new portions of their identity. For adults with ASD, getting older means an accumulation of limited social networks and the aging of their own family system, housing instability, and financial insecurity. This presentation presents results from 25 in-depth, in-person, life course interviews with adults aging with ASD. Results highlight the importance of transitions of social support for these adults as they seek to meet their needs in later life and features of community living that create more inclusivity of adults living with ASD, including opportunities for social engagement.

\section{SESSION 2550 (SYMPOSIUM)}

\section{THE BLUES AND OLDER MINORITY MUSICIANS: MORE THAN JUST MUSIC XXV \\ Chair: J.N. Migliaccio, Maturity Mark Services, White \\ Plains, New York}

The 1950s and 1960s were the heyday for hundreds of street-corner a-capella $\mathrm{R}$ n' $\mathrm{B}$ singing groups striving to match the fame and fortune- or at least "one-hit-wonder" status - of groups like The Flamingos, The Five Satins, The Skyliners, and The Drifters. This was the case for four friends coming up in the West Philadelphia neighborhoods suffused with the spirit of American Bandstand - THE BLENDTONES. After solid, but brief, success with their hit 45 single "She's Gone" on the Don-El label, penned by lead singer and song writer Robert Carpenter, 1st tenor Bill Keith, George "Sonny" Barnes, Clay Taylor, Henry Varlack, and Jim Dickerson, by 1961, many of the original group went off to pursue college educations and careers. Theirs is a story of high aspirations, brief success, record industry 